\title{
Technologies For Educating Deaf Children- A Systematic Literature Review
}

\author{
Caio C. S. Sousa ${ }^{1}$, Deller James ${ }^{1}$, Cassio L. Rodrigues ${ }^{1}$ \\ ${ }^{1}$ Institute of Informatics - Federal University of Goias (UFG) \\ Alameda Palmeiras - Campus Samambaia - Goiania - GO - Brazil \\ \{caiocsousa, deller, cassio\}@inf.ufg.br
}

\begin{abstract}
This paper presents a systematic review (SR) about technologies for educating the Deaf or Hard of Hearing (D/HH) children. A total of 21 papers published between 2010 and 2018 were examined. For this review, we aimed at analyzing empirical evidence concerning children education experiences and how the use of technology can influence this environment. We evaluated the following categories: age, grade level, technology, and topics taught. Results of this research show that using technology for educational purposes has positive outcomes such as sign language and vocabulary acquisition for children. However, accessibility guidelines should be taken into consideration when developing technology for the Deaf.
\end{abstract}

Resumo. Este artigo apresenta uma revisão sistemática $(R S)$ sobre tecnologias para educação de crianças surdas ou com deficiência auditiva. Um total de 21 artigos publicados entre 2010 e 2018 foram examinados. Para esta revisão, focamos em analisar evidências empíricas sobre experiências na educação infantil e como o uso da tecnologia pode influenciar esse ambiente. Avaliamos as seguintes categorias: idade, série, tecnologia e tópicos ensinados. Os resultados desta pesquisa mostram que o uso de tecnologia para fins educacionais é eficiente, como aquisição de linguagem de sinais e vocabulário para crianças. No entanto, as diretrizes de acessibilidade devem ser levadas em consideração ao criar tecnologias para o surdo.

\section{Introduction}

The inclusive model of education states that all children should have access to education, with the opportunity to be educated with moral and ethical support. An agreement was signed by several countries around the world, which outlined that inclusive education has to be for all children [Xie and Potměšil 2014]. To address this statement, we propose to review the education context of deaf children, regarding how technology can influence their educational environment.

Due to the increasing use of technology, education, in general, is more accessible. The $\mathrm{D} / \mathrm{HH}$ today that has access to education are benefited by having expanded opportunities to interact with society, communicate with people that are hearing, access to linguistic, and acceptance from the hearing [Xie and Potměšil 2014]. Even though education is essential, technology also has had a significant impact on the deaf in general. There was a time when deaf students could not communicate with people who were 
VIII Congresso Brasileiro de Informática na Educação (CBIE 2019)

Anais do XXX Simpósio Brasileiro de Informática na Educação (SBIE 2019)

not on their visual circle. With the advance of technology, long-distance communication like chat rooms and video conferences, deaf communication practices have improved [Denham and Battro 2012], thus enabling a better social and intellectual network for the $\mathrm{D} / \mathrm{HH}$.

The goal of this Systematic Review (SR) is to evaluate the effects has technologies for educating $\mathrm{D} / \mathrm{HH}$ children. This research consists of searching for primary and secondary studies related to the research topic and considering relevant digital bases. This paper is structured as follows. Section 2 describes the method applied to create this systematic review. Section 3 presents the results obtained from the research based on the categories of age, grade, topics taught, and technology. Section 4 contains the conclusion of this systematic review, based on the research question.

\section{Systematic Review Method}

This SR was elaborated using a trustworthy, rigorous, and auditable method. According to Kitchenham [A. Kitchenham 2007], an SR has the purpose of evaluating and analyzing available research relevant to the research question given. The stages included in this SR process consist of, planning the review, conducting the review, and reporting the review. The activities applied in this paper involved in these stages include but are not limited to:

- Analyzing the need for the review.

- Defining the research question(s).

- Create and maintain a review protocol.

- Identification and Selection of relevant primary and secondary research.

- Quality assessment by inclusion the of criteria.

- Maintaining and organizing research data.

- Writing descriptive summaries of results.

- Formatting and Writing reports.

\subsection{Search Strategies}

For this review we used a total of 5 digital libraries for searching information related to the research topic, the libraries are ACM digital library, Journal of Deaf Studies and Deaf Education (JDSDE), IEEE, Science Direct and Scopus. In order to effectively manage and organize this research, we used a software tool called StArt [Fabbri and Silva 2016] on its 3.3 beta version. This software was used to import most of the articles using the BibTeX format and divide the evaluation and classification process of the review and separate the articles according to their source and research string. Table 1 shows the library used for research and the related search string applied.

Table 1: Source and Search String

\begin{tabular}{ll}
\hline Source & Search String \\
\hline ACM & +("Technology" "Software" "application") +("Education" "Educating" \\
& "Schooling") \\
& $+($ ('Deaf" "Hard of Hearing" "Hearing Impaired") + (Children Kid) or \\
& +(Deaf "Hard of Hearing" "Hearing Impaired") + (Children Kids) \\
\hline
\end{tabular}


IEEE

JDSDE

Science Direct
((Education or Educating or Schooling) and (Technology or Software ) and

(Deaf or Hard of Hearing or Hearing Impaired) and (Children or Kids)) or

((Education) and (Technology) and (Deaf) and (Children))

(Education or Educating or Schooling) and (Technology or Software) and

(Deaf or "Hard of Hearing" or "Hearing Impaired") and (Children or Kids)

(Education or Educating or Schooling) and (Technology or Software ) and

("Deaf or Hard of Hearing" or "Hearing Impaired") and (Children or Kids) or

(Education and Technology and Deaf and Children)

(Education and Technology and Deaf and Children)

\subsection{Research Question}

The objective of this review is to understand the effects that technology has on teaching the deaf and hard of hearing children, so we aimed at answering the following research question: What empirical evidence is there concerning the positive impacts and outcomes of technological tools for the education of deaf children?

\subsection{Inclusive and Exclusive Criteria}

The papers that passed the selection and extraction process must have met the inclusive and exclusive criteria:

- Inclusive- Research published between Jan/2010 to Jan/2018.

- Inclusive- All research must be written in English.

- Exclusive- Duplicate research created by the same authors that have related topic, the least relevant one will be removed from this study.

- Exclusive- Research papers that are not relevant to the research objective.

\subsection{Study Identification, Selection, and Extraction}

The selection of the papers went through a three-step analysis. First, we executed a search using specific search strings in each library to find related studies. Second, we read the title and abstract and selected the most relevant papers and rejected the ones that did not fit the inclusion and exclusion criteria. Finally, we read each article thoroughly accepting and rejecting them based on the information each paper had on answering the research question. Figure 1 shows the three-step process, a total of 902 papers were initially identified for step one. The selection step then reduced the articles to 251. Finally, after the extraction took place a total of 21 articles were accepted. 
VIII Congresso Brasileiro de Informática na Educação (CBIE 2019)

Anais do XXX Simpósio Brasileiro de Informática na Educação (SBIE 2019)

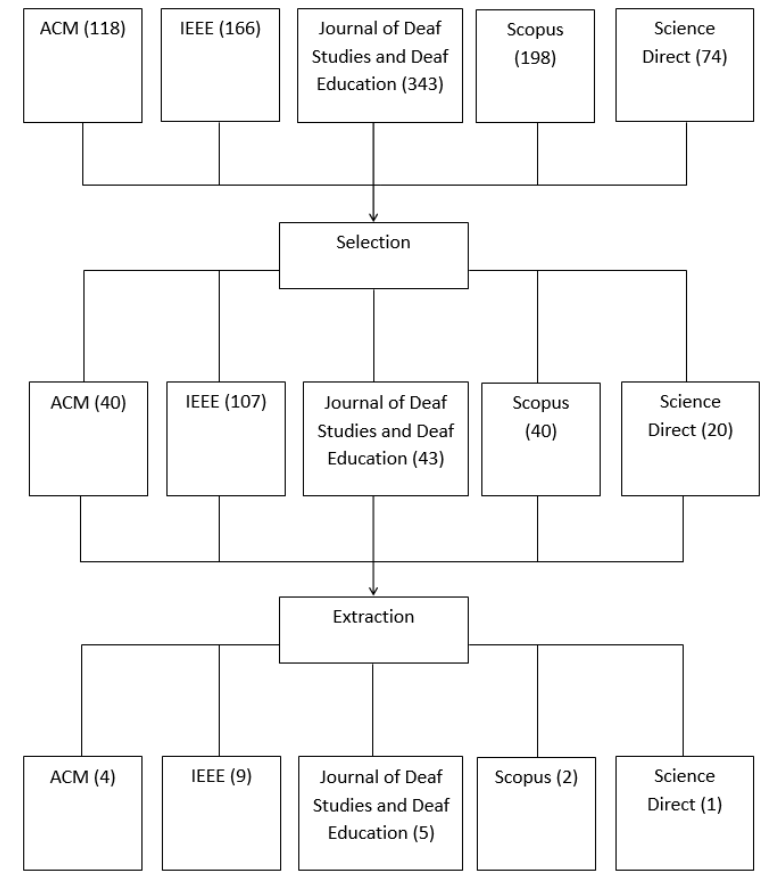

Figure 1. Studies Identification and Selection.

\subsection{Related Work}

We have identified in the literature one paper that is related to our study. The paper is a systematic literature review based on collaborative learning as an educational strategy for deaf children, collaborative learning in this context is referred to as group learning were students help each other to reach a common goal. [Aristizábal et al. 2017] had the objective of identifying how collaborative learning is being applied for educating deaf children and the kinds of technology that has been used in these environments. However, our paper has the goal of describing empirical evidence concerning the positive impacts of technological tools for the education of deaf children. We used a total of 5 digital libraries, out of these two were not used in the related work, we also had 902 papers identified and 21 papers accepted differently from 229 identified papers and 14 selected, our search string did not contain the word collaborative learning. The results we had differ from that of [Aristizábal et al. 2017] paper. We identified age or grade group of the children involved and subjects or topics being taught for each paper. We also analyzed evidence concerning the positive impacts that the result had like the students experience and feedback during the experiment. In our research, we suggest improving existing software accessibility, differently from [Aristizábal et al. 2017] that proposed a framework to promote the development of a collaborative tool.

\section{Results}

This section provides information from the 21 extracted articles, we created three categories and distributed each of the categories by authors in alphabetical order in 2 tables. Data that are not available has been labeled as not applicable $(\mathrm{N} \backslash \mathrm{A})$. The categories are:

- Age or Grade Group

- Topics Taught

- Technologies 
VIII Congresso Brasileiro de Informática na Educação (CBIE 2019)

Anais do XXX Simpósio Brasileiro de Informática na Educação (SBIE 2019)

\subsection{Age or Grade Group and Topics Taught}

This section provides information about children participating in the experiments. Age, grade level, and topics taught are covered here. Age distinction is necessary because the age of children is related to what is being taught and the learning expectancy of the target group. One cannot expect a group of 3 years old's to learn how to read and write effectively but could expect vocabulary gain.[A Davenport and Alber-Morgan 2017] states that children with good vocabulary tend to have better language results than children with limited vocabulary and that vocabulary gained at age 3 can have outcomes for children at age 9-10. According to [Akalin and Uluer 2014], the early stages of human life has significant impacts on language and cognitive development and that children between 2-7 years old knowledge are characterized by mental imagery, language, and symbolic thought. Research shows us that children that are $\mathrm{D} / \mathrm{HH}$ experiences delays in rules that affect linguistics units in the English language [Cannon and Easterbrooks 2011].

We conclude that some of the studies had references on the importance of teaching deaf children and why teaching at such an early stage can influence results throughout life. Emotional factors can also influence children learning experience [Gupta and Martin 2013] states that anxiety when learning math can initiate in first graders. Due to this evidence classifying the age group or grade level has become consistent evidence for this research.

Teaching occurred on a diverse number of subjects identified in the extracted research. Animation with 3D virtual space environment was customized for children to improve spatial perception and flexible thinking of D/HH children [Lin and Wang 2010]. One study had three different modules in one application, which are Jawi script, quiz, and memory games [Hussain 2014]. In Fernandez paper, music was an innovative proposal topic that has positive results in the integration of the class, which enabled a positive effect on the teaching and learning process [Chao-Fernandez and Román-García 2017]. Subjects were also taught in an organized order, first children were asked to read a story, then complete a set of exercise problems, last create a drawing to illustrate the story they read. TuxPaint drawing software was used to evaluate the student's readability of a set of stories [Mich 2011]. Finally,[Messier and Wood 2015] application helped children on their reading and vocabulary with three main tasks to measure, receptive pointing, expressively labeling, and word definitions.

Table 2: Age, Grade Group and Topic

\begin{tabular}{lll}
\hline Author & Age or Grade & Topic \\
\hline [A Davenport and Alber-Morgan 2017] & 3 years old & Vocabulary \\
[Akalin and Uluer 2014] & 9 to 16 years old & Teaching Sign Language \\
[Bouzid and khenissi 2016] & 10 to 14 years old & Vocabulary \\
[Cannon and Easterbrooks 2011] & 5 to 12 years old & Grammar \\
[Chaisanit and Suksakulchai 2010] & 9th grade & Vowel Training \\
[Chao-Fernandez and Román-García 2017]5 to 6 years old & Music \\
[Chebka and Essalmi 2015] & 10 to 11 years old & Arabic vocabulary \\
[Egusa and Sakai 2016] & 8 to 12 years old & Science and Japanese \\
\hline & & Continued on next page \\
\hline
\end{tabular}


VIII Congresso Brasileiro de Informática na Educação (CBIE 2019)

Anais do XXX Simpósio Brasileiro de Informática na Educação (SBIE 2019)

Table 2 - continued from previous page

\begin{tabular}{lll}
\hline Author & Age or Grade & Topic \\
\hline [Gupta and Martin 2013] & 8 to 16 years old & Math \\
[Hu and Wang 2013] & $\mathrm{N} \backslash \mathrm{A}$ & Language Abilities \\
[Hussain 2014] & 9 to 15 years old & Jawi Script and Games \\
[Lin and Wang 2010] & 10 to 13 years old & Virtual Games \\
[Messier and Wood 2015] & 4 to 9 years old & Reading and Vocabulary \\
[Mich 2011] & 8 to 14 years old & Reading and Drawing \\
[Mueller and Hurtig 2010] & 2 to 5 years old & Reading \\
[Priestley and Enns 2018] & 4 to 8 years old & Math and other Subjects \\
[Ryohei and Kumiko 2013] & 1 st to 6th grade & Theater and Storytelling \\
[Saud and Nasruddin 2016] & 7 to 8 years old & Alphabet, Numbers and \\
& & Jawi \\
[Vesel and Robillard 2013] & 4 th to 8th grade & Math \\
[Vettori and Mich 2011] & 8 to 14 years old & Reading Comprehension \\
[Wang and Paul 2011] & 7 to 11 years old & Literacy \\
\hline
\end{tabular}

Table 2 shows that 20 out of the 21 studies contains data regarding the age or grade level of the children ranging from 2 to 16 years old ranging, from 1 st to 9th grade. The children with ages between 10-11 years old had the highest average of participation. [Hu and Wang 2013] paper did not inform the children age or grade level but did inform the school name that is Nanjing School for Deaf located in China. [A Davenport and Alber-Morgan 2017] paper had only 2 participants attending school for the deaf and diagnosed with profound hearing loss. In [Akalin and Uluer 2014] study, tests were executed with a total of 28 children that were fluent in Turkish sign language. [Bouzid and khenissi 2016] had a total of 6 deaf participants with experiments performed at the Tunisian Association for deaf people (ATAS).

The studies have some diversity of topic taught, ranging from Japanese grammar to Jawi that is an Arabic alphabet created for writing the Malay language and music, among these subjects math, vocabulary and reading were the most common subjects taught. With the help of technology, we understand that teaching can be explored efficiently since some research had more than one subject being taught using only one type of application, which could also be used to evaluate what has been learned and help measure progress during the educational process.

For [Cannon and Easterbrooks 2011] intervention, 26 children participated in the study, and 8 teachers who taught kindergarten to fifth grade were recruited as a facilitator of the experiment. [Chaisanit and Suksakulchai 2010] evaluation had $10 \mathrm{D} / \mathrm{HH}$ students that attended the Setsatian School for the deaf who participated in the vowel training class. A study was implemented at the 2013/14 school year with 23 pupils aging from 56 years old attending the 3rd grade [Chao-Fernandez and Román-García 2017]. Finally, [Chebka and Essalmi 2015] experiment had a total of 38 participants, divided between 22 males and 16 females. The described studies varied greatly in the number of participants, age group, type of experiments, and experiment quantity. These variations show why a certain subject was being taught due to the level of the expected learning capabilities of the group. 
VIII Congresso Brasileiro de Informática na Educação (CBIE 2019)

Anais do XXX Simpósio Brasileiro de Informática na Educação (SBIE 2019)

\subsection{Technologies}

Technology can be used as a teaching tool, measure what has been taught, and also evaluate what was learned. This section aims at describing some of the technologies and how they have been applied during the experiments. Data such as navigation, usability, rules, accessibility, and other features regarding using the technology will also be described. According to [Chebka and Essalmi 2015], games can be used as a mechanism for stimulating social, motor, and cognitive skills. Depending on the background, some children can be more easily attracted to games than books or vice versa. [Gupta and Martin 2013] states that accessibility is fundamental to permit people with disabilities to comprehend and understand subjects, accessible formats include but are not limited to sign language and captioning support.

Table 3: Technologies

\begin{tabular}{lll}
\hline Technology & Description & Author \\
\hline Bilingual Program & Sign and Spoken English & [Priestley and Enns 2018] \\
Desktop/Web App & 3D Virtual Environment & [Lin and Wang 2010] \\
Desktop/Web App & Drawings & [Vettori and Mich 2011] \\
Desktop/Web App & e-drawing & [Mich 2011] \\
Desktop/Web App & e-learning & [Saud and Nasruddin 2016] \\
Desktop/Web App & Signing Math Dictionary & [Vesel and Robillard 2013] \\
Desktop/Web App & Software Program & [Cannon and Easterbrooks 2011] \\
Desktop/Web App & Speech Training Aid & [Hu and Wang 2013] \\
Desktop/Web App & Storytelling & [Chao-Fernandez and Román-García 2017] \\
e-book & Shared Reading & [Mueller and Hurtig 2010] \\
e-book & Vocabulary Intervention & [Messier and Wood 2015] \\
Mobile Application & Crossword Game & [Chebka and Essalmi 2015] \\
Mobile Application & Learning Game & [Hussain 2014] \\
Multimedia/Video & Beginning Literacy & [Wang and Paul 2011] \\
Multimedia/Video & Mathematics & [Gupta and Martin 2013] \\
Multimedia/Video & Puppet Theater & [Ryohei and Kumiko 2013] \\
Multimedia/Video & Vowel Training & [Chaisanit and Suksakulchai 2010] \\
Picture labeling & Race Track Game & [A Davenport and Alber-Morgan 2017] \\
Robots & Sign Language Game & [Akalin and Uluer 2014] \\
Video Game & Computer Game & [Bouzid and khenissi 2016] \\
Video Game & Kinect Sensor & [Egusa and Sakai 2016] \\
\hline
\end{tabular}

We identified a total of 8 distinct types of technology represented in table 3. Desktop and Web applications were the most common type of technologies. The bimodal-bilingual program is a unique technology because it focuses on developing proficiency in both languages speaking and signing [Priestley and Enns 2018]. [Chebka and Essalmi 2015] used a crossword game that enables the user to watch a sign language video and write the word in the corresponding location in the game, even though this technology was listed in the video game column a mobile version is also made available in the Arabic store of mobile apps with more than 1000 downloads. 
VIII Congresso Brasileiro de Informática na Educação (CBIE 2019)

Anais do XXX Simpósio Brasileiro de Informática na Educação (SBIE 2019)

[Egusa and Sakai 2016] papers describes a collaborative and interactive game that has activities that involve jumping and filling in the blank, the jumping stage uses a Xbox Kinect to evaluate when two players jump at the same time thus encouraging collaboration between users, the filling in the blank option allows selecting articles and inserting in sentences, this feature evaluates children grammar. The varied types of teaching tools provided a unique way for user interaction, thus enriching the usability of deaf children.

\section{Conclusion}

The research question: What empirical evidence is there concerning the positive impacts and outcomes of technological tools for the education of deaf children?

All of the research had a positive conclusion about the method applied for teaching deaf children. Out of these we highlighted 9 papers that had evidence regarding the impacts of the experiments. Experimental results show that two deaf preschoolers had sign language vocabulary acquisition, after the intervention [A Davenport and Alber-Morgan 2017]. Use of software improved the acquisition of sign-writing notation and could help promote bilingualism [Bouzid and khenissi 2016]. The given technology presents a productive environment for learning [Chaisanit and Suksakulchai 2010]. Children participating had improvements in music skills [Chao-Fernandez and Román-García 2017]. Collaborative learning was encouraged, and students had grammar acquisition after the intervention [Egusa and Sakai 2016]. Language skills have significantly improved with the help of Speech training aid system (STAS) as seen in Wang's paper [Hu and Wang 2013]. The e-drawing method applied helped children on their reading comprehension [Mich 2011]. Signing e-books can facilitate hearing parent's ability to provide their children with hearing loss those invaluable shared reading experiences [Mueller and Hurtig 2010]. Access to technology using signing math dictionary (SMD) may help students work independently as they learn math [Vesel and Robillard 2013]. Due to this evidence, we conclude that the use of technology has a positive impact on educating D/HH children.

In some cases, children struggled to use the given technology, we suggest that software developed for the $\mathrm{D} / \mathrm{HH}$ should be accessible and accessibility standards and guidelines provided by the Web Content Accessibility Guidelines (WCAG) and World Wide Web Consortium (W3C) should be considered [WCAG 2008, W3C 2019], to reduce difficulties in navigation, provide relevant consistent data and create acceptable user experience. This systematic review has the aim of identifying empirical evidence on technology for teaching the $\mathrm{D} / \mathrm{HH}$ children. All identified studies had some experimentation with positive impacts on educating $\mathrm{D} / \mathrm{HH}$ children. We suggest that educational tools should continue to be developed for $\mathrm{D} / \mathrm{HH}$ in general due to the results obtained from this review. The need to maintain the quality of the technology is also a concern, considering users usability and accessibility.

\section{Acknowledgement}

The authors would like to thank FAPEG for helping on funding this research. 
VIII Congresso Brasileiro de Informática na Educação (CBIE 2019)

Anais do XXX Simpósio Brasileiro de Informática na Educação (SBIE 2019)

\section{References}

A Davenport, C. and Alber-Morgan (2017). Effects of a picture racetrack game on the expressive vocabulary of deaf preschoolers. Journal of Deaf Studies and Deaf Education, 22:1-10.

A. Kitchenham, B. (2007). Kitchenham, B.: Guidelines for performing Systematic Literature Reviews in software engineering. EBSE Technical Report EBSE-2007-01. N/A.

Akalin, N. and Uluer, P. (2014). Non-verbal communication with a social robot peer: Towards robot assisted interactive sign language tutoring. In 2014 IEEE-RAS International Conference on Humanoid Robots, pages 1122-1127.

Aristizábal, L. F., Cano, S., Collazos, C. A., Solano, A., and Slegers, K. (2017). Collaborative learning as educational strategy for deaf children: A systematic literature review. In Proceedings of the XVIII International Conference on Human Computer Interaction, pages 38:1-38:8, New York, NY, USA. ACM.

Bouzid, Y. and khenissi, M. A. (2016). The effect of avatar technology on sign writing vocabularies acquisition for deaf learners. In 2016 IEEE 16th International Conference on Advanced Learning Technologies (ICALT), pages 441-445.

Cannon, J. E. and Easterbrooks (2011). Improving dhh students' grammar through an individualized software program. The Journal of Deaf Studies and Deaf Education, 16(4):437-457.

Chaisanit, S. and Suksakulchai, S. (2010). Interactive multimedia courseware of vowel training for the hearing impaired. In ICCAS 2010, pages 1196-1199.

Chao-Fernandez, R. and Román-García, S. (2017). Online interactive storytelling as a strategy for learning music and for integrating pupils with hearing disorders into early childhood education (ece). Procedia - Social and Behavioral Sciences, 237:17 - 22. Education, Health and ICT for a Transcultural World.

Chebka, R. and Essalmi, F. (2015). A crosswords game for deaf. In 2015 th International Conference on Information Communication Technology and Accessibility (ICTA), pages 1-6.

Denham, P. and Battro, A. (2012). Education of the deaf and hard of hearing in the digital era. Mind, Brain, and Education, 6(1):51-53.

Egusa, R. and Sakai (2016). Preparatory development of a collaborative / interactive learning game using bodily movements for deaf children. In Proceedings of the The 15th International Conference on Interaction Design and Children, IDC '16, pages 649-653, New York, NY, USA. ACM.

Fabbri, S. and Silva (2016). Improvements in the start tool to better support the systematic review process. In Proceedings of the 20th International Conference on Evaluation and Assessment in Software Engineering, EASE '16, pages 21:1-21:5, New York, NY, USA. ACM.

Gupta, P. K. and Martin, P. J. M. (2013). Comprehension of basic mathematics among children with hearing impairment using multimedia in accessible and non-accessible format a comparative study. In 2013 IEEE 63rd Annual Conference International Council for Education Media (ICEM), pages 1-11. 
VIII Congresso Brasileiro de Informática na Educação (CBIE 2019)

Anais do XXX Simpósio Brasileiro de Informática na Educação (SBIE 2019)

Hu, Y. and Wang, T. (2013). Development of speech training aid system for hearingimpaired children. pages 212-214. cited By 0.

Hussain, A. (2014). A usability testing on jfakih learning games for hearing impairment children. In The 5th International Conference on Information and Communication Technology for The Muslim World (ICT4M), pages 1-4.

Lin, C.-Y. and Wang, L.-C. (2010). Reducing cognitive load through virtual environments among hearing-impaired students. In 2010 Second Pacific-Asia Conference on Circuits, Communications and System, volume 1, pages 183-186.

Messier, J. and Wood, C. (2015). Facilitating vocabulary acquisition of children with cochlear implants using electronic storybooks. The Journal of Deaf Studies and Deaf Education, 20(4):356-373.

Mich, O. (2011). E-drawings as an evaluation method with deaf children. In The Proceedings of the 13th International ACM SIGACCESS Conference on Computers and Accessibility, ASSETS '11, pages 239-240, New York, NY, USA. ACM.

Mueller, V. and Hurtig, R. (2010). Technology-enhanced shared reading with deaf and hard-of-hearing children: The role of a fluent signing narrator. The Journal of Deaf Studies and Deaf Education, 15(1):72-101.

Priestley, K. and Enns (2018). Altering practices to include bimodal-bilingual (asl-spoken english) programming at a small school for the deaf in canada. The Journal of Deaf Studies and Deaf Education, 23(1):82-94.

Ryohei, E. and Kumiko (2013). Evaluation of interactive puppet theater based on inclusive design methods: A case study of students at elementary school for the deaf. In Proceedings of the 12th International Conference on Interaction Design and Children, IDC '13, pages 467-470, New York, NY, USA. ACM.

Saud, S. F. and Nasruddin, Z. A. (2016). Design of e-learning courseware for hearing impaired (hi) students. In 2016 4th International Conference on User Science and Engineering ( $i$-USEr), pages 271-276.

Vesel, J. and Robillard, T. (2013). Teaching mathematics vocabulary with an interactive signing math dictionary. Journal of Research on Technology in Education, 45(4):361389. cited By 1.

Vettori, C. and Mich, O. (2011). Supporting deaf children's reading skills: The many challenges of text simplification. In The Proceedings of the 13th International ACM SIGACCESS Conference on Computers and Accessibility, ASSETS '11, pages 283284, New York, NY, USA. ACM.

W3C (2019). World wide web consortium. www.w3.org.

Wang, Y. and Paul, P. (2011). Integrating technology and reading instruction with children who are deaf or hard of hearing: The effectiveness of the cornerstones project. American Annals of the Deaf, 156(1):58-68. cited By 9.

WCAG (2008). Web content accessibility guidelines 2.0. www.w3.org/TR/WCAG20/.

Xie, Y.-H. and Potměšil (2014). Children who are deaf or hard of hearing in inclusive educational settings: A literature review on interactions with peers. The Journal of Deaf Studies and Deaf Education, 19(4):423-437. 